\title{
FUTURE ORIENTED CORPORATE LEADERSHIP MODEL
}

\author{
Seyhani KOÇ \\ **Vildan DURMAZ \\ *The Air Logistics, Turkey \\ **Anadolu University, Turkey
}

\begin{abstract}
Studies on leadership had mostly been focused on individual boundries of leadership roles, but nowadays scholars such as Kornives et al., (2007), Möslein (2006), Kantabutra (2009, 2011) have worked on a progressive framework of leadership that everyone and every process is bounded by within the whole corporation and environment.

In the early 2000s while the business world witnessed global market competition, dynamic turbulent environmental change and increasing situational uncertainty; numerous lack of leadership and management issues resulted in corporate failures, cases of corruption and collapse as seen with Enron and Swiss airlines, thus sustaining growth became the most compelling mission for corporations. Surviving and sustaining the corporate leadership structure has become increasingly important for future corporations.
\end{abstract}

The purpose of our work is to present a corporate leadership framework which allows sustainable success to ensure stable growth based on shared positive cultural energy on a broad range of corporation activities. For that our research questions first are:

What are the differences between individual leadership and corporate leadership? and How corporate leadership could be structured?

Our study consists of a literature review about leadership, a brief comparison between individual leadership and corporate leadership and a proposed corporate leadership structure.

Keywords: Individual Leadership; Corporate Leadership; Leadership Differences; Leadership Prism: Leadership Model

\section{INTRODUCTION}

The globalization phenomena in recent years lead to more dynamic and challenging business environment (Fong, 2013:7). This business environment characterized by Homey et al. (2010:33) as VUCA:

- Volatility - The nature, speed, volume, magnitude and dynamics of change;

- Uncertainty -The lack of predictability of issues and events;

- Complexity - The confounding of issues and the chaos that surround any organisation; and

- Ambiguity - The haziness of reality and the mixed meanings of conditions.

According to American Management Association/Human Resource Institutes (2005) work on a global study of leadership; it is concluded that the increase in global competition, companies focusing more on their customers, the operating efficiency of their businesses, the accelerating pace of change and the need for innovation will challenge leaders most.

In the past managers and individual leaders did a good job in directing and managing their corporations, but nowadays in a dynamic business environment these past individual efforts are not enough. Idowu (2009:56) found that a frightening number of despondent companies and corporate organisations now exist all over the world due to various socio-economic, political, ecological and anthropological problems. According to Stevens et al. (2006) some of the serious leadership challenges facing business today and which are resulting 
Journal of Global Strategic Management | V. 9 | N. 1 | 2015-June | isma.info | 55-64 | DOI: 10.20460/JGSM.2015915628

in financial crises include, lack of accountability and irresponsible leadership arising from personal traits, background, education and professional skills of corporate officials (Idowu, 2009:58).

Corporations tend to be more entrepreneurial and try to identify business opportunities and avoid threats from the external environment in order to gain sustainable growth and profits (Fong, 2013:7). To strengthen corporations against the dynamic environmental changes and also to prevent, minimise or mitigate human based mistakes while humans nature is designed to make mistakes; designing a corporate leadership structure is a must.

\section{INDIVIDUAL AND CORPORATE LEADERSHIP}

Leadership is a concept which is often talked about, and which has generated a proliferation of literature, especially in the field of management and organisational science (Jones, 2005: 259). Despite its importance and studies for centuries there has been no generally agreement on its meaning both from scholars and practitioners (Avery 2004; Gill 2006; Western 2008) (Kantabutra, 2011:68). The definitional challenge on leadership literature is mostly western-oriented and individualistic, but there are few definitions which give leadership a collectivist meaning. According to Frank et al. (1996:11) there is no "best" style of leadership so to pursue profitable growth the corporations should use whatever works for them, long-term leadership success must be based on the realities of the organisation, leader and market.

Western (2008) highlights the diverse and subjective nature of leadership when he says it can have multiple forms and meanings and can be found in many different places, so it may be considered individual, collective, or a process depending on where we are looking. What is common is that leadership operates in the realm of human relations (Kantabutra, 2011:68). While Coglisera and Brighamb (2004:776) implies that leadership, is the process of influence and reflects a more complex and dynamic phenomenon than that of an individual factor.

Bass (1990:4), described leadership as an interaction between two or more members of a group that often involves a structuring or restructuring of the situation and the perception and expectations of the members. Warren Bennis and James O'Toole define leadership as the ability to move human hearts to challenge people and make them want to scale steep peaks (Long, 2001) as well as Yukl (2008:8) describes leadership as the process of influencing others to understand and agree about what needs to be done and how to do it, and the process of facilitating individual and collective efforts to accomplish shared objectives. While Kornives et al., (2007:13) describes leadership as a relational and ethical process of people together attempting to accomplish positive change. As Kakabadse \& Kakabadse (1999) define leadership as a 'capability to identify pertinent pathways forward when direction is obscure (Davies \& Kakabadse, 2011:246). The GLOBE studies define leadership as the ability of an individual to influence, motivate, and enable others to contribute towards the effectiveness and success of the organisations of which they are members (House et al., 2004:15). These definitions show leadership is an individual behaviour that influences and directs followers.

Between 1950 and the 1960s stable environment leader-centric leadership approach assumed that individuals were responsible for the construction of the future organisation structure. At the end of 2000's corporations tried to get leaders with heroic leadership skills but when the heroic leaders had gone then companies faced crisis, faltering and subsequent collapses such as Enron and Swiss Air. Corporations no longer can rely on a single individual at the top to handle the complexity and uncertainty of the global dynamic environmental situations, according to (Avery, 2004) multiple leaders are valuable because as people cope with heterogeneous and dynamic environments, the knowledge and issues become too complicated for only a few leaders to understand (Jing \& Avery, 2008:72). By the lack of individual leadership in a dynamic, competitive and unstable world the 'need' for flexible and decentralized leadership systems (Cooper, 2005:233) revealed according to collective, empowered, shared and distributed leadership practices. Leadership comes to be seen as a shared set of activities rather than a single person's trait, and a sense of ownership of group outcomes arises (Schein, 2010:210).

Nowadays theses collectivist leadership style is not sufficient future-oriented corporations needs a proactive and collaborative leadership structure. Suriyankietkaew (2013:174) and Sooksan Kantabutra \& Suparak Suriyankietkaew (2012:68-69) stated that the new direction of leadership studies focuses are common, with some varying degrees that they share similar concepts and characteristics that move away from leader- 
centric, less command and control from the top, but rather focusing on shared or collective team work of multiple members of the organisation to achieve common goals.

At individual leader aspect, leadership is a functional issue of human activities in an organisation, so most individualized leadership theories, focus on dyadic or small group phenomena, rather than influences over the organisational processes (Du et al., 2013:157), but according to Volckmann (2005:290); leadership is the emergence of leader's behaviours in a system over time as the corporation is a collaborative organic living system which is part of a broader environment influenced by every micro level circumstance that they are engaged with and having a set of shared values.

The word 'corporate' is something connected with a company, a business entity or a corporation. A company is like a human being which can sue and be sued in its corporate name. The only difference between a registered company/corporation and a human being is that a company has no biological life. But a company has a longer life span than a human being (Idowu, 2009:58). According to Ardichvili \& Manderscheid (2008:621) individual based leader development is necessary for leadership, but it is not sufficient as Toole (2001) stated. It requires to be integrated and understood in the context of others, social systems, and organisational strategies, missions, and goals in a collectivist style. And Kelly (2004) implied that besides luck and external circumstances, successful corporate business needs to: define culling standards of performance, design values and organisation that engage their people, and set tangible paths for growth. Thus Corporate Leadership is the process of an organisation's collaborative actions under the same culture through becoming a world-class company. In recent years while change has been getting faster, global competition increases, stakeholder willingness differs; the importance of corporate leadership has been raised in importance. Kelly (2004:389) reminds us that corporate growth and success are not random events of corporate evolution but depends on the visible hand of leadership that drives, shapes and evolves businesses in good times and bad.

Corporate leadership's characteristics in terms of organisations boundaries (Figure 1);

- It is a factor in the changing environment that depends on the internal dynamics based on the strategies developed for the industry.

- Covers organisational arrangements according to the external dynamic environment through the future.

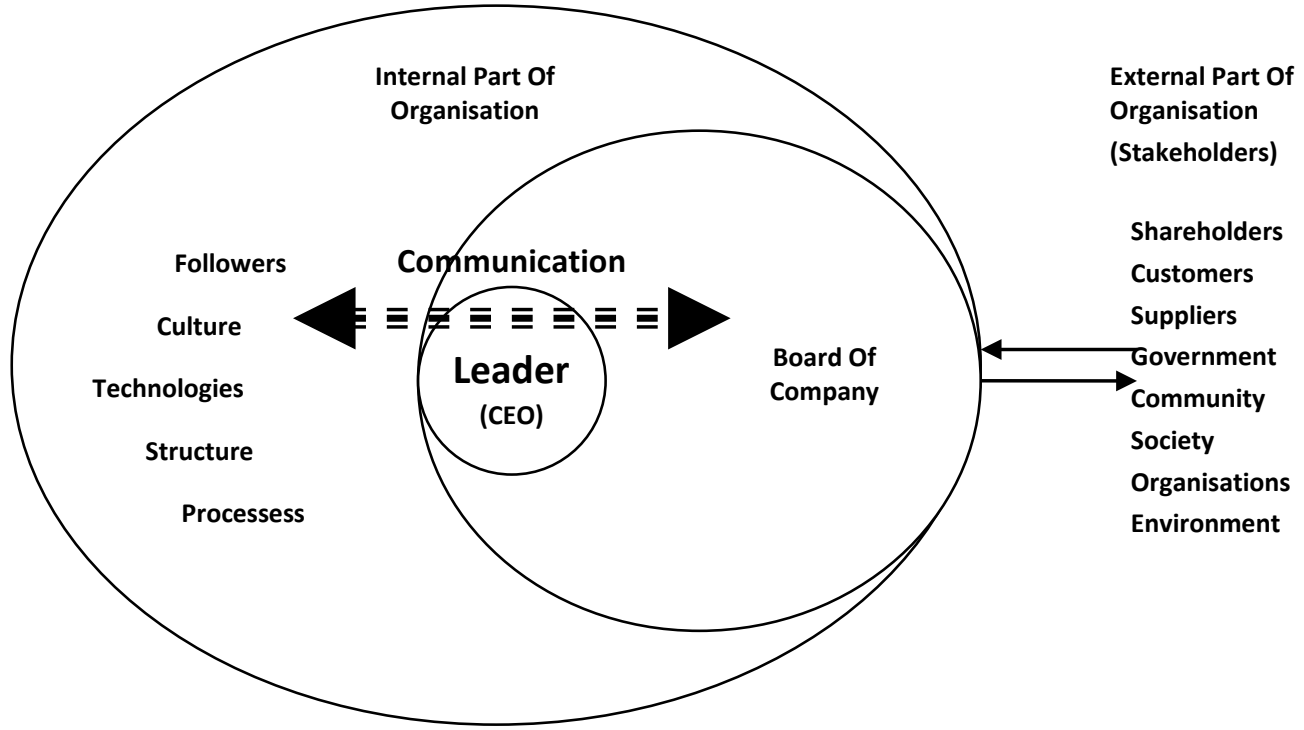

Fig. 1. Boundaries of Organisation (Adapted From Ruth Barratt \& Nada KoracKakabadse, 2002:34).

\section{DIFFERENCES BETWEEN INDIVIDUAL AND CORPORATE LEADERSHIP}

There are common aspects between individual and corporational leadership, i.e. both need followers, visionary strategic view and movement, values and cooperation, decision-making (Weiss \& Kolberg, 
2003:67; Roomi \& Harrison, 2011:5). In a recent attempt to structure leadership research, Freeman et al. (2006) conclude that five core themes are common amongst most literature. These include;

- the leader with his or her traits and characteristics,

- the followers,

- the outcomes of leadership,

- the processes and skills used by leaders, and

- the situation or context in which leadership occurs.

While leader is a key instrument to any effort in organisations, Schein (2010) stated change requires a much broader approach of leadership and culture; because individualism has a limited influence if it is not supported by the organisation's core elements (culture, people, strategies, systems, and structures). As shown on Table 1 corporational leadership is not a collection of traits (Roomi \& Harrison, 2011:5) nor influencing or motivating followers, through corporate leadership you are building a living legacy for your business and industry (Weiss \& Kolberg, 2003:206). According to Jones (2012:15-16) size, market share and profit do not define corporate leadership; innovation, common vision, taking time for reflection, adaptability and steady profits are the characteristics.

Table 1. Differences between individual leadership and corporate leadership.

\begin{tabular}{lll}
\hline Objectives & Individual Leadership & Corporate Leadership \\
\hline Limitations & $\begin{array}{l}\text { Depending on past experiences and } \\
\text { leader's capabilities solving daily } \\
\text { problems and reaching profitability / } \\
\text { efficiency targets. }\end{array}$ & $\begin{array}{l}\text { Stable and sustainable growth } \\
\text { according to viable future with } \\
\text { innovative thinking. }\end{array}$ \\
\hline Results & $\begin{array}{l}\text { Leader's perspective, organisational } \\
\text { resources and environment. }\end{array}$ & $\begin{array}{l}\text { Differing ideas, organisation, potential } \\
\text { resource lackness and boundried } \\
\text { organisational field, interactions with } \\
\text { external environment. }\end{array}$ \\
\hline Organisational Structure & Effectiveness, efficiency and & $\begin{array}{l}\text { Steady profit, development, growth } \\
\text { and sustainability }\end{array}$ \\
\hline Leadership Type & Stable and bureaucratic & Adaptable and networked \\
\hline Time and Risk & Traditionally, task-oriented & Shared, strategy-oriented and organic \\
\hline
\end{tabular}

Kotters (Pavlica \& Jarošová, 2013:222) defined the distinction between the interpersonal ("How one leads") and organisational aspects ("What one leads") of leadership (Table 2). According to Pavlica \& Jarošová's (2013) research the interpersonal aspect largely revolves around a self-assertive, directive style versus an inclusive, supportive style. The organisational part revolves around the technical details of execution in the short term versus planning ahead to position the organisation with a strategy for the future.

Table 2: A model of opposing behaviours (Pavlica \& Jarošová, 2013:222)

\begin{tabular}{ll}
\hline & Leadership \\
\hline Interpersonal & Inclusive and supportive \\
(How one leads) & Empowers \\
& Listens \\
& Supports \\
\hline Organisational & Long-Term Strategic \\
(What one leads) & Direction \\
& Growth \\
& Innovation \\
\hline
\end{tabular}




\section{FUTURE ORIENTED CORPORATE LEADERSHIP MODEL}

Recent literature on leadership has some common perceptions about the challenges of the twenty-first century related to globalization, new markets, growing environmental stress, usage of non-renewable resources, social issues, financial crises, technological development, the rapid pace of and demand for change, work intensification and issues of sustainability (Zborková, 2012:442). What really the world of tomorrow be like, is not known; it will be different, more complex, faster and more culturally diverse (Schein, 2010:365). The wide range of leadership theories clearly demonstrates that, in order to get the leadership of future, corporations must not only consider the traits and effectiveness of individual leaders but also the whole transformed business and dynamic environment.

Nye (2008:xi), states leadership as a social relationship with three key components - leaders, followers, and the contexts in which they interact. While Peele (2005:191) states that leadership should be thought of in terms of six dimensions- the character of the leader; the followers; the organisational/societal context; the problems which confront the leader; the techniques the leaders use to gain support for their agenda/position; and the effects of leadership, which allow for a clear balance and cross-contextual applicability.

While culture influences the strategy, structure, procedures (Schein, 2010:374-375), corporate leadership is based on corporations' culture, leader development system, effective collaborativation and communication and the way which the parts in the Corporate Leadership Prism (Figure 2) will relate to each other. Through corporation Leadership Prisms responsible and collaborative work and under their vision in which success is achieved the whole corporation will efficiently lift to a world-class level. Besides these corporational leadership activities affect corporations culture through transforming the needs and aspirations of the followers and stakeholders by developing individual leaders aligned with the corporation's vision.

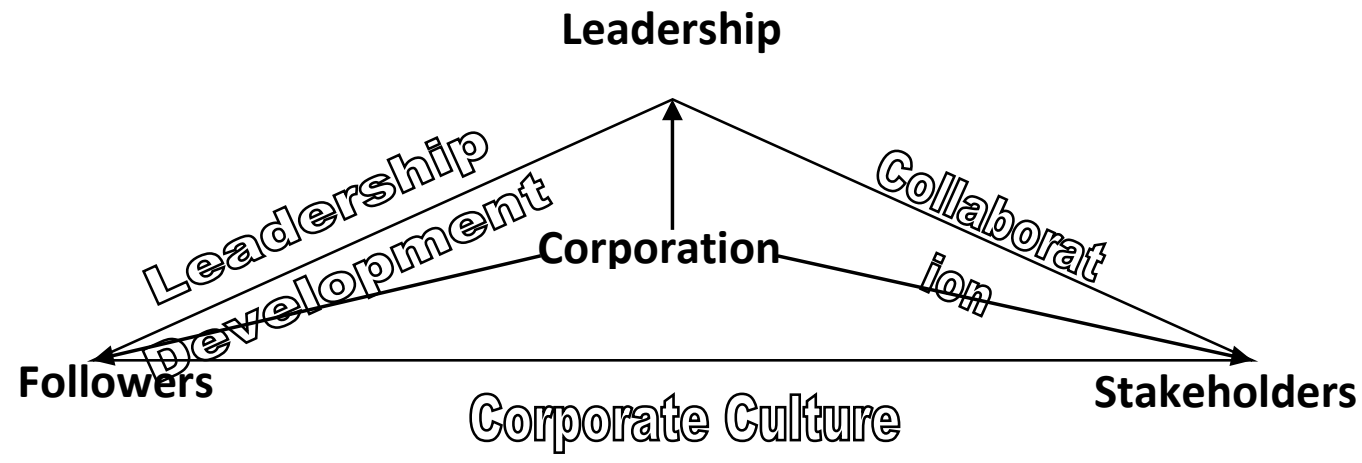

Fig. 2. Corporate Leadership Prism.

Hutchinson (1983:34) stated that corporations sustain from the challenges they met when the five following fundamental corporate purposes are mutually and optimally served.

- to provide socially needed goods and services of acceptable quality at reasonable prices.

- to create and maintain an internal organisation and culture in which personal and group achievement, growth and fulfilment thrive.

- to attain and sustain net income sufficient both to perpetuate the enterprise and yield a return on investment satisfactory to the stockholders involved.

- to protect, preserve, and enhance social, cultural and physical environmental conditions wherever the operations of the enterprise are located and wherever its products and services may go.

- to communicate openly, honestly, and voluntarily relevant information concerning all of these activities to all constituencies concerned. 


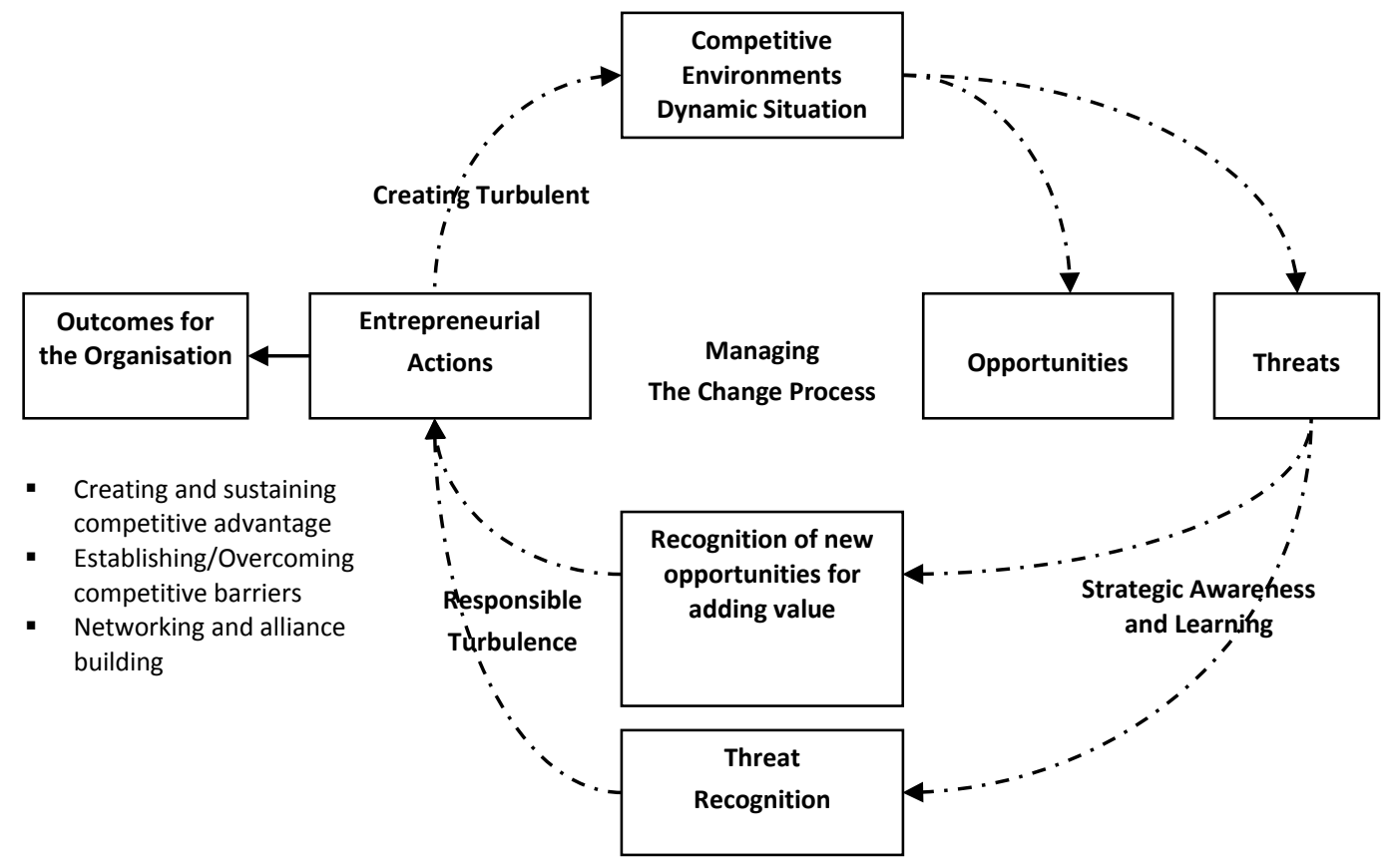

\section{Fig. 3. Corporational Leadership Process (Thompson, 1999:288).}

Besides Hutchinson, Thompson (1999) contends that corporational leadership success is based on the environment (E), resources (R) and values (V). He argued that successful organisations have created and sustained E-V-R congruence at both the strategic and operational levels. For being a strong competitor in the market they should understand the requirements and be aware of the dynamics; so to manage the change pressures they should develop strategic, structural and managerial capabilities (Figure 3).

Huff \& Möslein stated that, especially in large-scale enterprises, the art of leadership is most often subject to relatively rigid management processes and takes place in an institutional context (Huff \& Möslein, 2004:254). So Huff \& Möslein (2004) propose a generic leadership system linked to structure, strategy, and culture within the company.

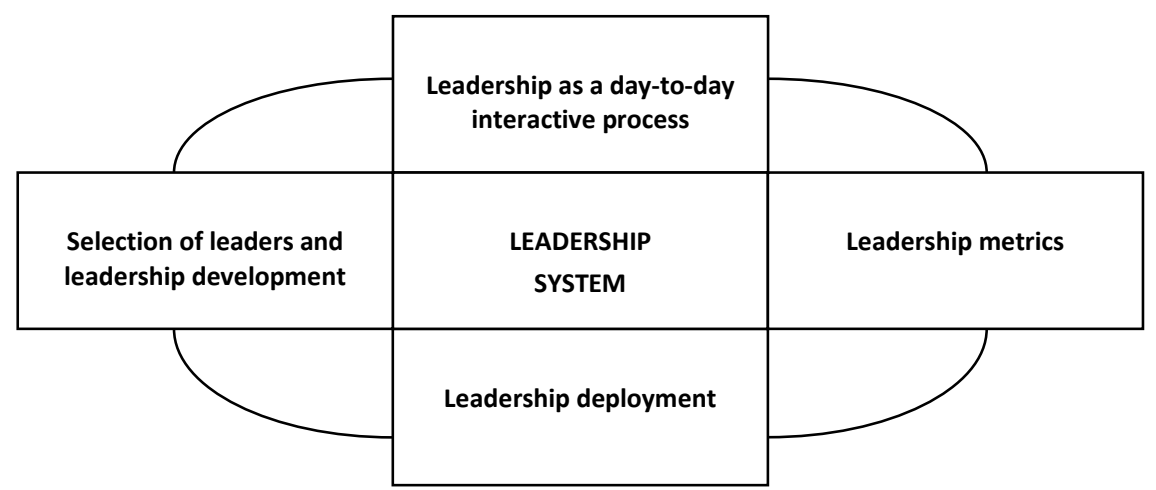

Fig. 4. Generic Leadership System (Source: Möslein, 2006).

The act of corporation leadership process provides empowered followers with innovative thinking, deliberative decision making based on deeper organisational knowledge under control and care of strategic and shared individual leadership valuing stakeholders through achieving greater corporate strength. Thus corporate longevity depends on a balance of individual, corporation and external forces. Davies \& Kakabadse (2011) states that a balance for leadership longevity depends on the inner strength of both the individual and 
the organisation; for this they propose a model on the ongoing flow of crucial knowledge and data to create, care for, control and calibrate the strategic longevity of the organisation. Dalakoura (2010:434) argued organisations that apply a leadership development program to everyday activities in all levels of the organisation would have an overall positive increase in the corporates' leadership.

Separating the leader from the leadership context is impossible so our proposed corporate leadership model consists of the corporate Leadership Prism (Figure 2) that has a more adaptive structure to the changing environment engaged with corporations’ long term strategies (Figure 5).

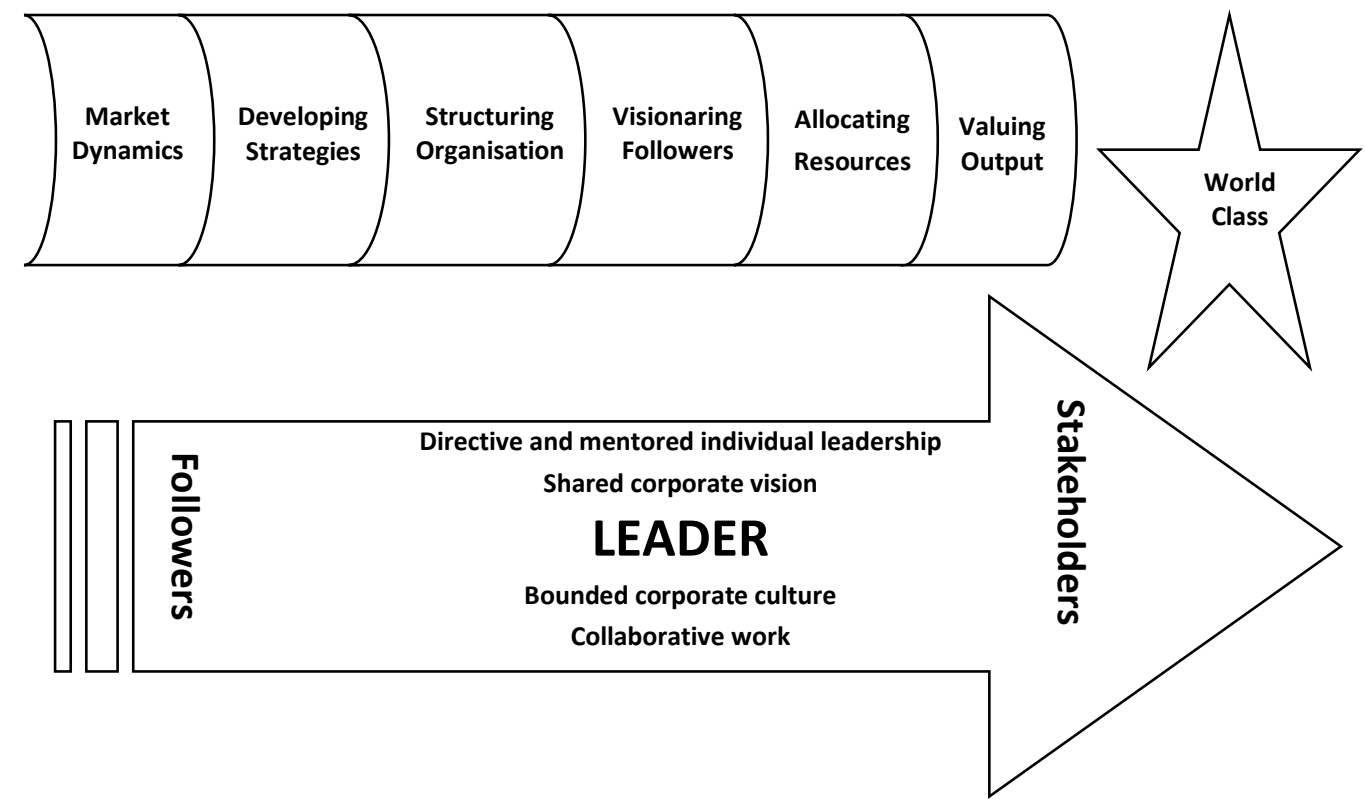

Fig. 5. Corporate Leadership Process.

Corporates achieve the congruence needed to sustain success in a VUCA world only by making continual shifts in people, processes, technology and structure (Homey et al. 2010:33). So corporations should ensure the list below when structuring the corporational leadership system;

- Determination of the vision according to the corporations core competencies,

- Vision should be engaged with corporational culture,

- Corporation's structure should be transformed according to the vision,

- According to future expectations and needs and in line with vision, strategies should be determined,

- Adapting strategies and vision to the corporation's business units and applications,

- Enabling effective communication in the Leadership Prism,

- Integration with external environment and effectively managing customer and stakeholder relationships,

- Allocating resources effectively and punctually to ensure that they are in the right place at the desired quality in line with corporate strategies,

- Empowering and developing corporations' members for ensuring development of inner organisation and the organisations within the organisational field,

- Continuous control of the organisational processes and environment.

Maybe the most important aspect of leadership agility focused on growth strategy has been transitioning from internally to an externally focused company (Homey et al. 2010:36). The proposed corporational leadership model not only integrates business processes through strategies, also builds communication within the Leadership Prism throughout the whole corporation based on corporate culture which drives internal 
dynamism that develops the contributions of individuals so that corporations can thrive with greater excellence according to the corporation's strategies.

\section{CONCLUSION}

Since the world we are living in is becoming more complex and dynamic it appears that no theory is universal and research on leadership has become more distinctive and detailed. Leadership seemed to be a critical process for corporations strategically challenging them from internal and external threats and pressures in order to survive. Leadership studies are mostly about trait, behaviour, and mission and situationally based on individuals; nowadays leadership models are focusing on the collectivist and participative side of leadership theories. Individual leaders seem to be the most important factor for sustainability in complex, rapidly changing, competitive markets, however they are not enough to make a progress in the way through being a world-class organisation, as a result, the whole corporation system is needed to get account.

Corporational leadership is a dynamic process, in order to become a world class company behind a sustainable vision, based on a culture that enables followers and stakeholders to work collaboratively with their leaders' positive influence and mentoring that allows corporates to realise opportunities in the rapid changing competitive markets. So the corporations which sustain in future will be the ones which could structure a more appropriate leadership model that balances their needs with their capabilities through their Corporate Leadership Prism in the changing environment according to their visions.

For further studies; Corporational Leadership Prims relationship with corporation's performance from a system analysis viewpoint and also a leadership development system according to Corporational Leadership Prims could be researched. 


\section{REFERENCES}

AMA (2005). Leading Into The Future, American Management Association/Human Resource Institute: NY. USA. (http://www.amajapan.co.jp/j/pdf/HRI_Leading_into_the_Future_E.pdf)

Ardichvili, A. \& Manderscheid, S.V. (2008). Emerging practices in leadership development: An introduction. Advances in Developing Human Resources, 10(5), 619-631.

Bass, B. M. (1990). Handbook of Leadership: Theory, Research and Managerial Applications (3rd ed.). New York: The Free Press,

Hutchinson, Charles T. (1983). Prospectus for Corporate Leadership. Business Horizons, 32-36.

Coglisera, C. C. \& Brighamb, K. H. (2004). The intersection of leadership and entrepreneurship: Mutual lessons to be learned. The Leadership Quarterly, 15, 771-799.

Dalakoura, A. (2010). Differentiating leader and leadership development: A collective framework for leadership development. Journal of Management Development, 29(5), 432-331.

Davies, L. \& Kakabadse, N. (2011). Individual and Corporate Leadership Longevity, Proceedings of the European Conference on Management, Leadership \& Governance, 246 -253.

Du, S., Swaen, V., Lindgreen A. \& Sen, S. (2013). The Roles of Leadership Styles in Corporate Social Responsibility. J Bus Ethics, 114, 155-169.

Fong, C., Ng Y., Sin-Howe, T. P., \& Ai-Na S. (2013). Does Leadership and HRM Matter on Corporate Entrepreneurship? Human Resource Management Research, 3(1), 7-10.

Frank, Gertz, D. \& Porter, John (1996). Leadership for growth. Strategy \& Leadership, 24 (5), 6-11.

Freeman, R. E., Martin, K., Parmar, B., Cording, M. \& Werhane, P. H. (2006). Leading through values and ethical principles. In: Burke, R. J. and Cooper, C. L. (Eds.): Inspiring leaders. London, England: Routledge Publications.

House, R. J., Hanges, P. J., Javidan M., Dorfman, P. W., \& Gupta, V. (2004). Culture Leadership and Organizations: The GLOBE study of 62 Societies. Thousand Oaks: SAGE Publications.

Homey, N., Pasmore, B. \& O'Shea, T. (2010). Leadership Agility: A Business Imperative for a VUCA World. People \& Strategy, Volume 33/Issue 4, 33-38.

Idowu, Amos A. (2009). Challenges of Leadership in Corporate Management and Turnaround. International Business and Tourism Society, 56-73.

Kantabutra, S. (2009). Toward a behavioral theory of vision in organizational settings. Leadership \& Organization Development Journal. Vol. 30 No. 4, 319-337.

Kantabutra, S. (2011). Sustainable leadership in a Thai healthcare services provider. International Journal of Health Care Quality Assurance. Vol. 24 No. 1, 67-80.

Kantabutra, S. \& Suriyankietkaew, S. (2012). Examining Relationships Between Organic Leadership And Corporate Sustainability: A Proposed Model. The Journal of Applied Business Research, Volume 28, Number 1, 67-80.

Kelly, J.(2004). Corporate Leadership Reflections of a CEO and CEO Advisor. Long Range Planning, 37, 389-398.

Kornives, S. R., Lucas, N., \& McMahon, T. R. (2007). Exploring leadership: For college students who want to make a difference (2nd ed.). San Francisco: Jossey-Bass.

Kelly, J. (2004). Executive Summaries, Corporate Leadership: Reflections of a CEO and CEO advisor. Long Range Planning, 37, 389.

Long, W. P. (2001). Corporate leadership succession, Business Times. 
Möslein, K. M., Neyer, A. K. \& Reichwald, R. (2006). Leading Innovation: The Role of Leadership Systems for the Leadership of Boundary Spanning Innovation, Paper presented at the 26th SMS Annual International Conference 2006, Vienna. (Received: 05.04.2015 http://wi1.uni-erlangen.de/)

Nye, J. S. (2008). The Powers to Lead. New York: Oxford University Press.

Pavlica, K. \& Jarošová, E. (2013). Versatile Leadership and Organisational Culture. Proceedings of the European Conference on Management. Leadership \& Governance, 221-229.

Peele, G. (2005). Leadership and Politics: A Case for a Closer Relationship?. Leadership, 1:2, 187-204.

Roomi, M. A. \& Harrison, P. (2011). Entrepreneurial Leadership: What Is It and How Should It Be Taught?, International Review of Entrepreneurship 9(3). Senate Hall Academic Publishing. (Received: 05.04.2015 http://www.senatehall.com/uploads/fck/1038RoomiHarrison9_3.pdf)

Barratt, Ruth \& Kakabadse, Nada Korac (2002). Developing reflexive corporate leadership. Corporate Governance, 2 (3), 32-36.

Jing, F. F. \& Avery G. C. (2008). Missing Links In Understanding The Relationship Between Leadership And Organizational Performance. International Business \& Economics Research Journal, Volume 7, Number 5, 67-78.

Jones, A. M. (2005). The Anthropology of Leadership: Culture and Corporate Leadership in the American South. Leadership, Vol. 1, 259-278.

Jones, R. B. (2012). Corporate Leadership. USA: Adhesives \& Sealants Industry.

Thompson, J. L. (1999). A strategic perspective of entrepreneurship. International Journal of Entrepreneurial Behaviour \&, Research, Vol. 5 No. 6, 279-296.

Schein, E. H. (2010). Organizational Culture and Leadership, San Francisco: John Wiley \& Sons, Inc.

Suriyankietkaew, S. (2013). Emergent Leadership Paradigms For Corporate Sustainability: A Proposed Model. The Journal of Applied Business Research, Volume 29, Number 1, 173-182.

Volckmann, R. (2005). Assessing executive leadership: an integral approach. Journal of Organizational Change Management, 18 (3), 289-302.

Weiss, T., \& Kolberg, S. (2003). Coaching competencies and corporate leadership. CRC Press LLC.

Yukl, G. (2008). Leadership in organizations (7th ed.). New Jersey: Prentice-Hall.

Zborková, J. (2012). Corporate Leadership in the 21st Century and its Influence in Sustainability Reporting. Proceedings of the European Conference on Management, Leadership \& Governance, 442-448. 